\title{
The modification of acrylic denture base resin as materials for artificial teeth: Effect of hydroquinone and methyl methacrylate monomer
}

\author{
Pornchiwin Banjong $^{\mathrm{a}}$, Natthawika Sankham ${ }^{\mathrm{a}}$, Watchara Duangnga ${ }^{\mathrm{a}}$, Uraiwan Intatha ${ }^{\mathrm{a}, \mathrm{b}}$, \\ Nattakan Soykeabkaew ${ }^{\mathrm{a}, \mathrm{b}}$, Sitthi Duangphet ${ }^{\mathrm{a}, \mathrm{b}, *}$ \\ a School of Science, Mae Fah Luang University, Chiang Rai 57100 Thailand \\ b Center of Innovative Materials for Sustainability (iMatS), Mae Fah Luang University, Chiang Rai 57100 \\ Thailand
}

*Corresponding author, e-mail: sitthi.dua@mfu.ac.th

Received 15 Oct 2019

Accepted 28 Mar 2020

\begin{abstract}
The purpose of this project is to modify denture base resin for use as artificial teeth material. Generally, resin for denture base will harden within a few minutes but the working period for artificial teeth shaping is about 30 min. Adding methyl methacrylate (MMA) monomer to dilute accelerator and adding hydroquinone (HQ) as an inhibitor are considered in order to extend the solidifying time of denture base resin. The ratios of denture base resin/MMA in this study were 3:1, 2:2 and 1:3 v/v and the concentration of HQ was varied from $0.01-0.05 \mathrm{wt} \%$. The results indicated that both HQ and MMA prolonged solidification time of denture base resin and HQ was more effective in increasing working time than MMA. However, the introduction of HQ and MMA decreased mechanical properties of the resin including flexural strength, flexural modulus and hardness, so further modifications such as addition of fillers are required.
\end{abstract}

KEYWORDS: artificial teeth, denture base, methyl methacrylate, acrylic resins, hydroquinone

\section{INTRODUCTION}

Artificial teeth are important in oral rehabilitation when natural teeth are lost. The most commonly used materials for artificial teeth nowadays are ceramic based (porcelain) and polymer based (acrylic). Though ceramic based teeth possess some inherent advantages, such as color superiority, color stability, and comparatively improved wear resistance qualities [1], they tend to fracture or detach from denture bases frequently due to incompatibilities in the coefficient of thermal expansion and high modulus of elasticity $[2,3]$. For acrylic based teeth, when compared with ceramic, they are less brittle, lighter, have less water absorption, easier to grind and polish, more compatible with the denture base, easier to repair and more affordable [3]. However, there are some drawbacks such as poor abrasion resistance and not being durable [4].

The acrylic material used in modern prosthodontic rehabilitation is a mixture of 2 components where one is in liquid form and the other is in powder form. The liquid part typically contains an acrylic monomer, crosslinking agent, inhibitor and accelerator. Hydroquinone (HQ) is commonly used as inhibitor to stabilize the acrylic monomer from premature polymerization via heat or light prior to mixing with the powder [5]. The powder part normally is composed of poly(methyl methacrylate) (PMMA), initiator and pigment. The polymerization process can be activated at room temperature and ambient air via the free radical chain reaction due to the redox reaction of the peroxide-amine system [5]. When the powder and liquid parts are mixed, the material changes subsequently from sandy stage to stringy, then dough-like, rubbery and stiff stages. The dough-like stage is the best condition for the material to be manipulated and this period is generally called "working time" and the mixing time to reach the dough-like stage is called "dough forming time".

In Thailand, acrylic dental teeth have not yet been manufactured and they have been imported at high prices. Not only the production constraint where manufacturers are not willing to supply the raw materials, but the color and size of imported teeth are also not matched with Thai citizens. Fortunately, the production of acrylic denture base 
and also raw materials are currently available in Thailand. The basic components of denture base and artificial teeth are quite similar, so the modification of denture base acrylic materials to produce acrylic artificial teeth is currently being considered. However, the short working period is the major restriction for commercial realization. Practically, the minimum required working time for teeth shaping process is about $20 \mathrm{~min}$, while the working time of denture base resin provided only less than $10 \mathrm{~min}$. The extension of working time, thus, is one of the main criteria to utilize the denture base resin for acrylic dental teeth. Diluting accelerator or increasing inhibitor are the potential methods for extending the working period. Therefore, dilution of the accelerator by adding MMA monomer and a change of the inhibitor concentration by adding HQ were studied. The effects of MMA monomer content and HQ concentration on dough forming and working times were investigated. To meet the basic requirements of artificial teeth, the mechanical properties in terms of flexural strength and hardness were evaluated.

\section{MATERIALS AND METHODS}

\section{Materials}

The commercial denture resin Orthoplast ${ }^{\circledR}$ components, purchased from Vertex Dental (The Netherlands), were supplied in powder and liquid form. The powder component mainly contained PMMA powder and benzoyl peroxide (BPO) whereas the liquid component was mostly composed of MMA, N,N-Dimethyl-p-toluidine (DMPT) and hydroquinone (HQ). MMA monomer (Merck KGaA, Germanny) and HQ (Ajax Finechem, Australia) were used as received.

\section{Sample preparation for dough forming time and working time}

PMMA cement was prepared by mixing the Orthoplast ${ }^{\circledR}$ powder $(2.3 \mathrm{~g})$ and liquid component $(2 \mathrm{ml})$ according to the manufacturer recommendations (Vertex-Dental, The Netherlands). MMA monomer was added into the liquid component and it was varied from $0.5-1.5 \mathrm{ml}$. HQ was also added into the mixture and it was varied from $0.01-0.05 \mathrm{wt} \%$, with respect to the total mass of formulation (Table 1 ).

The dough forming time starts from mixing of powder and liquid components until reaching the dough like stage where the cement no longer sticks to the surgical gloves $[6,7]$. Similarly, the time to rubbery stage was measured from the beginning
Table 1 Formulations of PMMA cement specimens.

\begin{tabular}{lcccc}
\hline \multirow{2}{*}{ CODE } & \multicolumn{3}{c}{ Liquid (ml) } & Powder $(\mathrm{g})$ \\
& Orthoplast ${ }^{\circledR}$ & MMA & HQ (wt\%) & Orthoplast ${ }^{\circledR}$ \\
\hline M0.0HQ0.00 & & & 0.00 & \\
M0.0HQ0.01 & \multirow{2}{*}{2.00} & 0.00 & 0.01 & 2.30 \\
M0.0HQ0.03 & & & 0.03 & \\
M0.0HQ0.05 & & & 0.05 & \\
\hline M0.5HQ0.00 & & & 0.00 & \\
M0.5HQ0.01 & \multirow{2}{*}{1.50} & \multirow{2}{*}{0.50} & 0.01 & 2.30 \\
M0.5HQ0.03 & & & 0.03 & \\
M0.5HQ0.05 & & & 0.05 & \\
\hline M1.0HQ0.00 & & & 0.00 & \\
M1.0HQ0.01 & \multirow{2}{*}{1.00} & \multirow{2}{*}{1.00} & 0.01 & 2.30 \\
M1.0HQ0.03 & & & 0.03 & \\
M1.0HQ0.05 & & & 0.05 & \\
\hline M1.5HQ0.00 & & & 0.00 & \\
M1.5HQ0.01 & \multirow{2}{*}{0.50} & \multirow{2}{*}{1.50} & 0.01 & 2.30 \\
M1.5HQ0.03 & & & 0.03 & \\
M1.5HQ0.05 & & & 0.05 & \\
\hline
\end{tabular}

of mixing to the time when cement cannot change to another shape $[6,7]$. The working time is the period between dough forming time and the time to rubbery stage.

\section{Mechanical characterization \\ Specimen preparation}

The specimens were prepared via the compression method. The mixed cements were filled into a rectangular-shaped mold (63 $\mathrm{mm} \times 13 \mathrm{~mm} \times 2.5 \mathrm{~mm}$ ). The mold was then placed in a hot-pressing machine. The acrylic based resin was cured for $25 \mathrm{~min}$ at the selected temperature depending on the formulation.

\section{Flexural testing}

The three-point flexural properties were measured by The Instron 5566 Universal Testing Machine (UTM), Ithaca, New York according to ASTM D790. The cross-head speed of $5 \mathrm{~mm} / \mathrm{min}$ was used in this testing. The length support span was set at $50 \mathrm{~mm}$. The values reported were the average values of 5 specimens for each condition. The equations to calculate flexural strength $(\sigma)$ and flexural modulus (E) are

$$
\begin{aligned}
& \sigma=3 F L / 2 b d^{2}, \\
& E=F L^{3} / 4 \delta b d^{3},
\end{aligned}
$$

where $F$ is the maximum force applied, $\delta$ is the deflection, $L$ is the length of support span, $b$ is the width of the sample and $d$ is the thickness of the sample. 


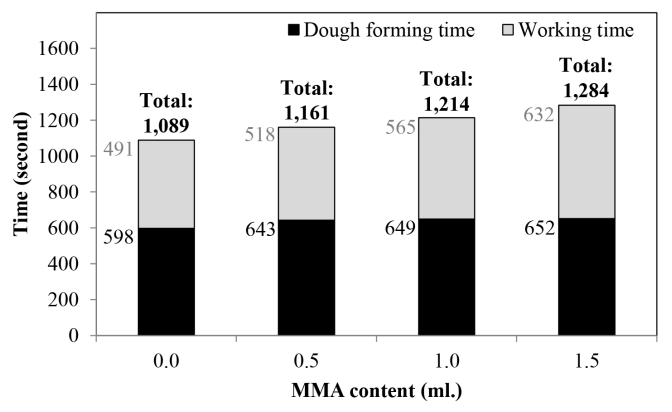

Fig. 1 Effect of MMA monomer content on the dough forming and working times of PMMA specimens.

\section{Microhardness testing}

The microhardness test was performed with a MMTX3, Mutsuzawa, Japan for all specimens. The force was applied to the midpoint of the base materials by a diamond tip. Then, the diagonals of the resulting indention were measured by a microscope and calculated to give hardness values. The values reported were the average of 5 spots for each condition under the load of $2942 \mathrm{mN}$.

\section{RESULTS}

\section{Dough forming time and working time Effect of MMA monomer}

Fig. 1 presents the effect of adding MMA monomer on dough forming and working times of commercial PMMA cement. The Orthoplast ${ }^{\circledR}$ resin without added MMA monomer showed the shortest for both times. Incorporation of MMA monomer in the liquid component can extend dough forming time as well as working time. Dough forming time was stretched from 598 to $652 \mathrm{~s}(9.0 \%)$ and working time was prolonged from 491 to $632 \mathrm{~s}(28.7 \%)$, when $1.5 \mathrm{ml}$ of MMA monomer was added.

\section{Effect of $H Q$}

The dough forming time and working time of the Orthoplast $\AA$ resin with added HQ and various MMA content are shown in Fig. 2. For Orthoplast ${ }^{\circledR}$ resin without added MMA monomer (Fig. 2(a)), the incorporation of HQ significantly affected the dough-forming and working times. With increasing HQ concentration, the dough-forming and working times were prolonged. They can be extended to $762 \mathrm{~s}(27.4 \%)$ and $1353 \mathrm{~s}(175.6 \%)$ for dough forming time and working time, respectively, when $0.05 \mathrm{wt} \%$ of HQ was added. The same trend was observed in Orthoplast $\AA$ resin cooperated with MMA monomer (Fig. 2(b-d)). With the increase of HQ concentration, the dough forming time and working time were increased. However, when compared with the same HQ concentration but different MMA content, no significant differences were found.

\section{Mechanical properties}

The flexural strength and flexural modulus of the specimens for various formulations after curing are shown in Fig. 3. The incorporation of both MMA and HQ showed significantly reduced flexural properties. When the concentration of HQ was further increased, the flexural strength and flexural modulus were greatly decreased. In the same way, MMA also reduced flexural strength and flexural modulus except for the HQ0.01 series. With HQ concentration of $0.01 \mathrm{wt} \%$, the flexural strength and flexural modulus were highest when $0.5 \mathrm{ml}$ of MMA was replaced. However, these values were unremarkable when compared with the original formulation (M0.0HQ0.00).

The similar trend of flexural properties was also presented for microhardness results as shown in Fig. 4. With increase of the amount of MMA monomer to Orthoplast $\AA$, the hardness subsequently reduced. For HQ inhibitor, the most hardness was obtained at $0.01 \mathrm{wt} \%$ of $\mathrm{HQ}$ for all MMA series. Moreover, the hardness tended to decrease with increasing HQ content.

\section{DISCUSSION}

This study focused on extending the working time of self-curing Orthoplast $\AA$ resin which usually was applied for the denture base. The hardening period for denture base resin is generally completed within a few minutes, however the shaping process or working time for acrylic dental teeth requires more than $20 \mathrm{~min}$ (1200 s).

The concept of adding MMA monomer to Orthoplast ${ }^{\circledR}$ resin is to extend working time by diluting accelerator (e.g., DMPT). Only the optimum molar ratio of BPO to amine provides polymerization with the minimum time [8]. This specific ratio more or less leads to reduced polymerization rate. Orthoplast ${ }^{\circledR}$ resin is a fast curing resin which means the $\mathrm{BPO} /$ amine molar ratio was already produced to be optimum. Adjusting the BPO/amine molar ratio by adding MMA monomer disturbed this optimal point and resulted in prolonging the working time. Though the working time can be slightly prolonged by adding MMA monomer, the significant drop of flexural properties and hardness must be noted. The reduction of molecular weight is the reason 

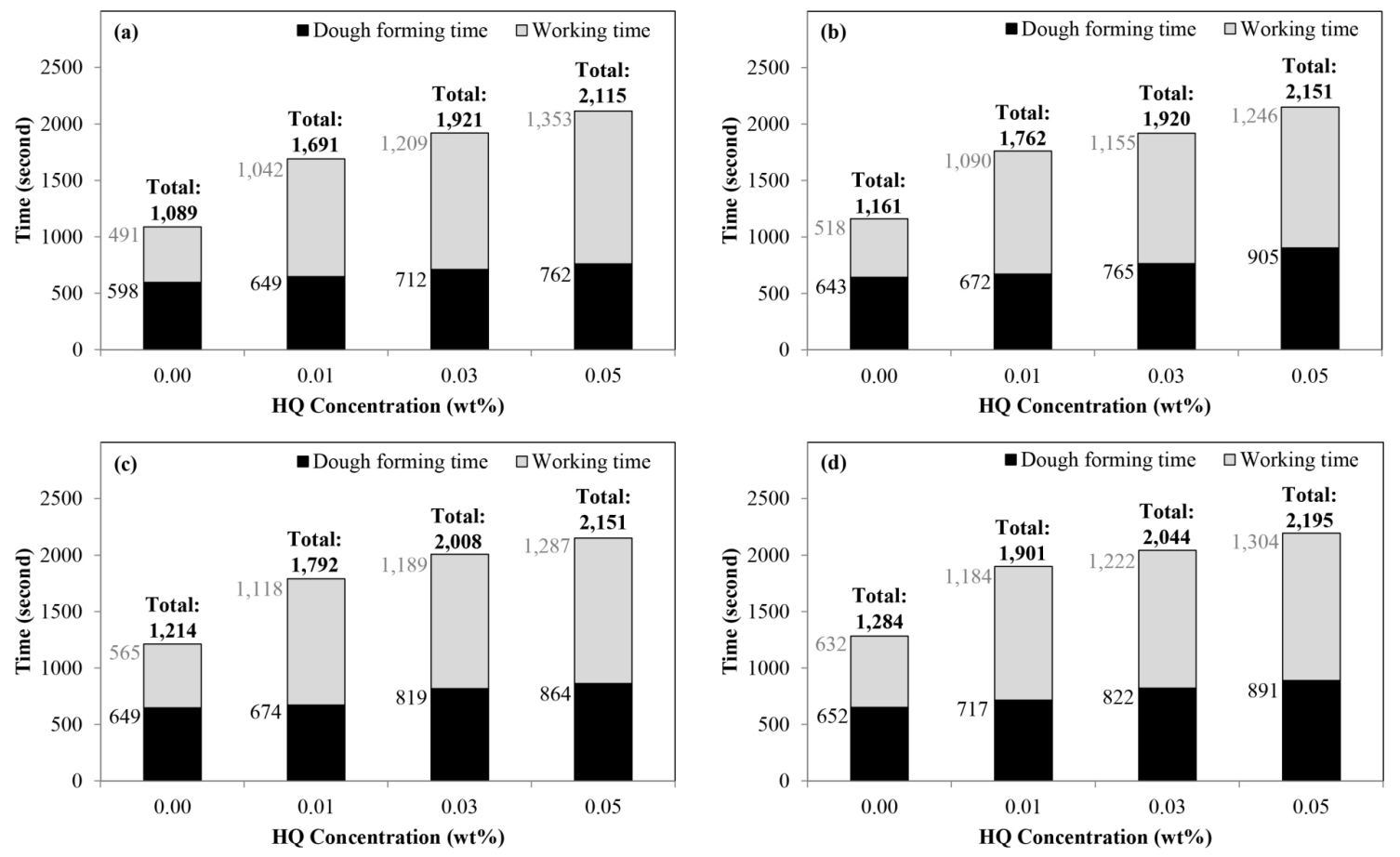

Fig. 2 Effect of HQ inhibitor on the dough forming and working times of PMMA specimens in various MMA series; (a) MMA0 series, (b) MMA0.5 series, (c) MMA1.0 series and (d) MMA1.5 series.
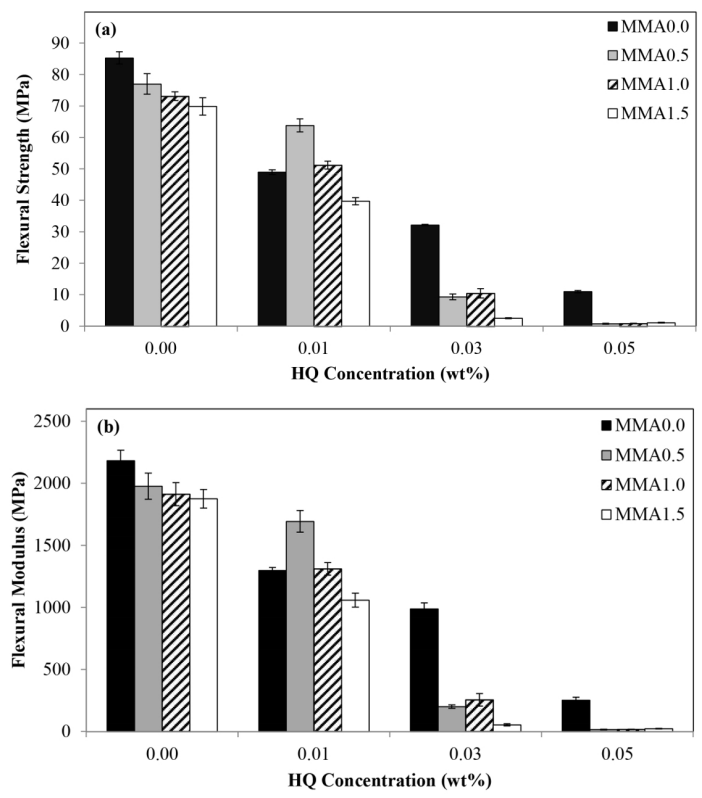

Fig. 3 Effect of HQ on mechanical properties of PMMA specimens for various MMA series: (a) flexural strength and (b) flexural modulus. The data are presented as the mean $\pm \operatorname{SD}(n=5)$.

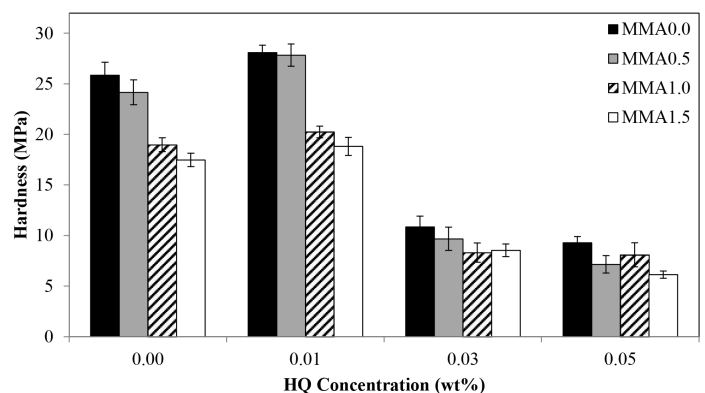

Fig. 4 Effect of HQ on microhardness of PMMA specimens for various MMA series. The data are presented as the mean $\pm \operatorname{SD}(n=5)$.

for the decline of mechanical properties. Achilias and Sideridou [9] studied the effect of BPO/DMPT initiation systems on the polymerization of MMA and found that increasing of the molar ratio of BPO to amine decreased molecular weight and increased the polydispersity index. The dilution of DMPT by adding MMA monomer causes an increasing $\mathrm{BPO} / \mathrm{amine}$ ratio and induces, subsequently, a molecular weight reduction. As a result, the mechanical properties will be reduced. 
Utilization of inhibitor is another promising way to extend the working time. Inhibitors are commonly added to suppress the polymerization of monomers and prevent premature polymerization during shipment or storage [10]. Inhibitors readily react with active radicals to form stable or less reactive radicals. So, they stop polymerization until the inhibitors are consumed. In the $\mathrm{BPO} / \mathrm{amine}$ system, including BPO/DMPT, the BPO and amine are unable to react with the monomers due to the action of inhibitors during the induction period [11] that delays the working period for a longer time. Compared with MMA addition, combination of Orthoplast ${ }^{\circledR}$ resin and HQ showed better efficiency in terms of prolonging working time. For mechanical properties, however, HQ brought a tragic effect to the PMMA specimens. The reduction of flexural properties and hardness may be attributed to the increase of residual monomer content. These findings are in accord with that of Vázquez, Deb and Bonfield [12], who found that increasing BPO concentration resulted in shorter dough forming time and less residual monomer as well as increased ultimate tensile strength and Young's modulus. Decrease in the concentration of BPO was found to allow more residual monomer which acted as an internal plasticizer leading to a drop of strength [12]. Therefore, additional amounts of HQ which reduce BPO concentration contribute to higher amounts of residual monomer and reduce the mechanical properties.

\section{CONCLUSION}

The incorporation of MMA monomer and HQ provides working time extension which would benefit the shaping processing for artificial teeth production. This allows the modification of denture base acrylic materials to produce acrylic artificial teeth. The addition of MMA monomer and HQ however showed a marked decrease of the mechanical properties and hence the incorporation of fillers should be considered to improve this limitation.

Acknowledgements: Financial supports from National Research Council of Thailand (NRCT) and Mae Fah Luang University (MFU), Thailand are gratefully acknowledged. Information and reagents from Hexa Ceram Co., Ltd. are also appreciated.

\section{REFERENCES}

1. Zhang Y, Kelly JR (2017) Dental ceramics for restoration and metal veneering. Dent Clin North Am 61, 797-819.

2. Ghazal M, Albashaireh ZS, Kern M (2008) Wear resistance of nanofilled composite resin and feldspathic ceramic artificial teeth. J Prosthet Dent 100, 441-448.

3. Stoia AE, Sinescu C, Pielmusi M, Enescu M, Tudor A, Romînu RO, Romînu M (2011) Tensile testing, a method used to demonstrate the effect of organic solvents on acrylic teeth denture base resin bond strength. Int $J$ Bio and Biom Eng 5, 9-17.

4. Porat M, Parvizi J (2013) Polymethylmethacylate bone cement. In: Parvizi J, Klatt B (eds) Essentials in Total Hip Arthroplasty, 1st edn, Slack Incorporated, New Jersey, pp 63-68.

5. Samad HA, Jaafar M (2009) Effect of polymethyl methacrylate (PMMA) powder to liquid monomer $(\mathrm{P} / \mathrm{L})$ ratio and powder molecular weight on the properties of PMMA cement. Polymer Plast Technol Eng 48, 554-560.

6. Turner RC, Atkins PE, Ackley MA, Park JB (1981) Molecular and macroscopic properties of PMMA bone cement: Free-radical generation and temperature change versus mixing ratio. J Biomed Mater Res 15, 425-432.

7. Klineberg I, Earnshaw R (1969) Physical properties of synthetic resin baseplate materials. Part II. Coldcuring acrylic resins. Aust Dent J 14, 255-263.

8. Bowen RL, Argentar HA (1973) Method for determining the optimum peroxide to amine ratio for selfcuring resins. J Appl Polym Sci 17, 2213-2222.

9. Achilias DS, Sideridou ID (2002) Study of the effect of two BPO/amine initiation systems on the freeradical polymerization of MMA used in dental resins and bone cements. J Macromol Sci A 39, 1435-1450.

10. Pascual B, Gurruchaga M, Ginebra MP, Gil FJ, Planell JA, Goñi I (1999) Influence of the modification of $P / L$ ratio on a new formulation of acrylic bone cement. Biomaterials 20, 465-474.

11. Landuyt KL, Snauwaert JE, Munck JD, Peumans M, Yoshida Y, Poitevin A, Coutinho E, Suzuki K, et al (2007) Systematic review of the chemical composition of contemporary dental adhesives. Biomaterials 28, 3757-3785.

12. Vázquez B, Deb S, Bonfield W (1997) Optimization of benzoyl peroxide concentration in an experimental bone cement based on poly(methyl methacrylate). $J$ Mater Sci Mater Med 8, 455-460. 